$05,07,11$

\title{
Ориентационный магнитный фазовый переход, индуцированный при ударном нагружении сплава $\mathrm{Fe}-\mathrm{Cr}-\mathrm{Co}$
}

\author{
(С) Ю.В. Судьенков, В.М. Сарнацкий, И.В. Смирнов \\ Санкт-Петербургский государственный университет, \\ Санкт-Петербург, Россия \\ E-mail: y.sudenkov@yandex.ru
}

(Поступила в Редакцию 29 марта 2016 г.

В окончательной редакции 13 июля 2016 г.)

\begin{abstract}
В процессе исследований прочностных характеристик при высокоскоростном деформировании сплавов $\mathrm{Fe}-\mathrm{Cr}-\mathrm{Co}$ обнаружено, что в результате ударного нагружения в образцах и их фрагментах возникает значительная остаточная намагниченность, обусловленная ориентационным магнитным фазовым переходом. В работе определены пороговые давления магнитного фазового перехода и исследовано распределение остаточной намагниченности в образцах.
\end{abstract}

Работа осуществлена в рамках проекта РНФ № 15-19-00182.

DOI: 10.21883/FTT.2017.02.44048.113

\section{1. Введение}

Магнитотвердые материалы на основе сплавов системы $\mathrm{Fe}-\mathrm{Cr}-\mathrm{Co}$ [1] обладают удачным сочетанием высоких магнитных свойств с коррозионной стойкостью, достаточной прочностью и пластичностью. Прочность и пластичность таких сплавов широко исследовались в квазистатических испытаниях, например в работах [1-4], однако информация о прочности и пластичности при ударных нагрузках весьма ограничена. Влияние перестройки структуры материала на процессы динамической деформации и разрушения недостаточно изучено, поэтому поведение сплавов $\mathrm{Fe}-\mathrm{Cr}-\mathrm{Co}$ при ударных нагрузках плохо прогнозируемо.

В работах $[5,6]$ представлены результаты исследования динамических свойств ферримагнитного сплава с различной термомагнитной обработкой, а также изменения микроструктуры материала после ударной нагрузки микро- и субмикросекундной длительности. В результате исследований была обнаружена намагниченность образцов после ударной нагрузки, при этом до динамического воздействия образцы не проявляли магнитных свойств. В продолжение исследований $[5,6]$ в настоящей работе представлены результаты исследований остаточной намагниченности образцов после ударного воздействия и параметров фазового перехода.

\section{2. Материал и методика исследований}

Исследования проводились для сплава $\mathrm{Fe}-25 \% \mathrm{Cr}-12 \% \mathrm{Co}(0.9 \% \mathrm{Si}, 0.09 \% \mathrm{Mn}, 0.025 \% \mathrm{C})$. Образцы сплава представляли собой диски $\varnothing 40 \times(4-9) \mathrm{mm}$, предварительно подвергнутые различной термообработке $[5,6]$ : № 1 - закалка, затем старение в магнитном поле, № 2 - закалка, затем старение без магнитного поля и № 3 - закалка.
Для генерации хорошо контролируемых ударных нагрузок в твердых телах была разработана методика, использующая симметрию электрического взрыва тонких фольг и лазерную интерферометрическую диагностику скорости движения свободной поверхности нагружаемых объектов [7]. Разработанный метод позволяет проводить лабораторные исследования процессов деформации и разрушения при высокоскоростном нагружении материалов в диапазоне длительностей $\sim 0.1-1 \mu \mathrm{s}$ и давлений до $20 \mathrm{GPa}$, существенно повысив информативность ударно-волновых экспериментов.

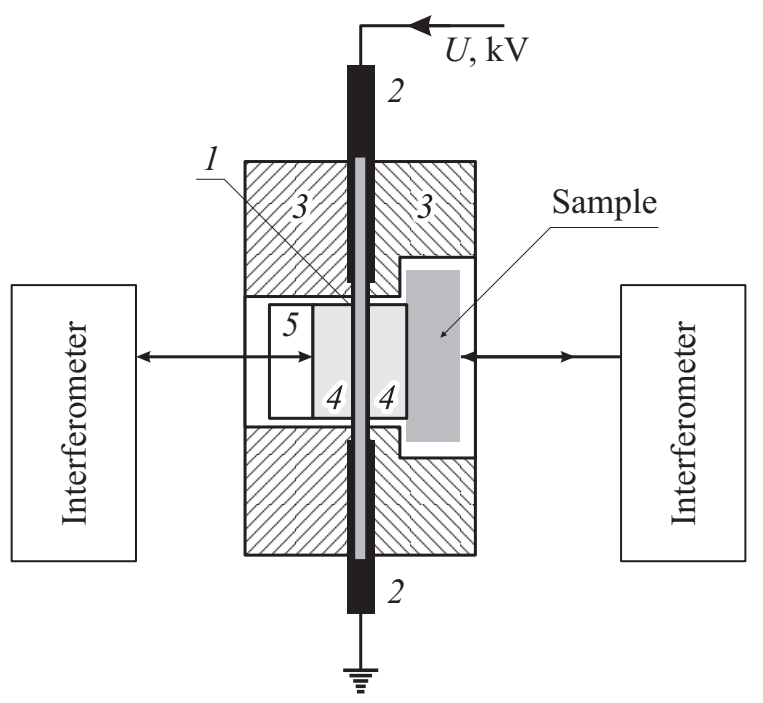

Рис. 1. Схема методики исследования ударно-волновых процессов в твердых телах при использовании симметрии электрического взрыва фольг, где $1-\mathrm{Al}$ фольга $0.03 \times 20 \times 35 \mathrm{~mm}$, 2 - электроды, 3 - корпус из диэлектрика, 4 - волноводы $\varnothing 20 \mathrm{~mm}, 5$ - оптическое зеркало (ПММА, кварцевое стекло, сапфир). 

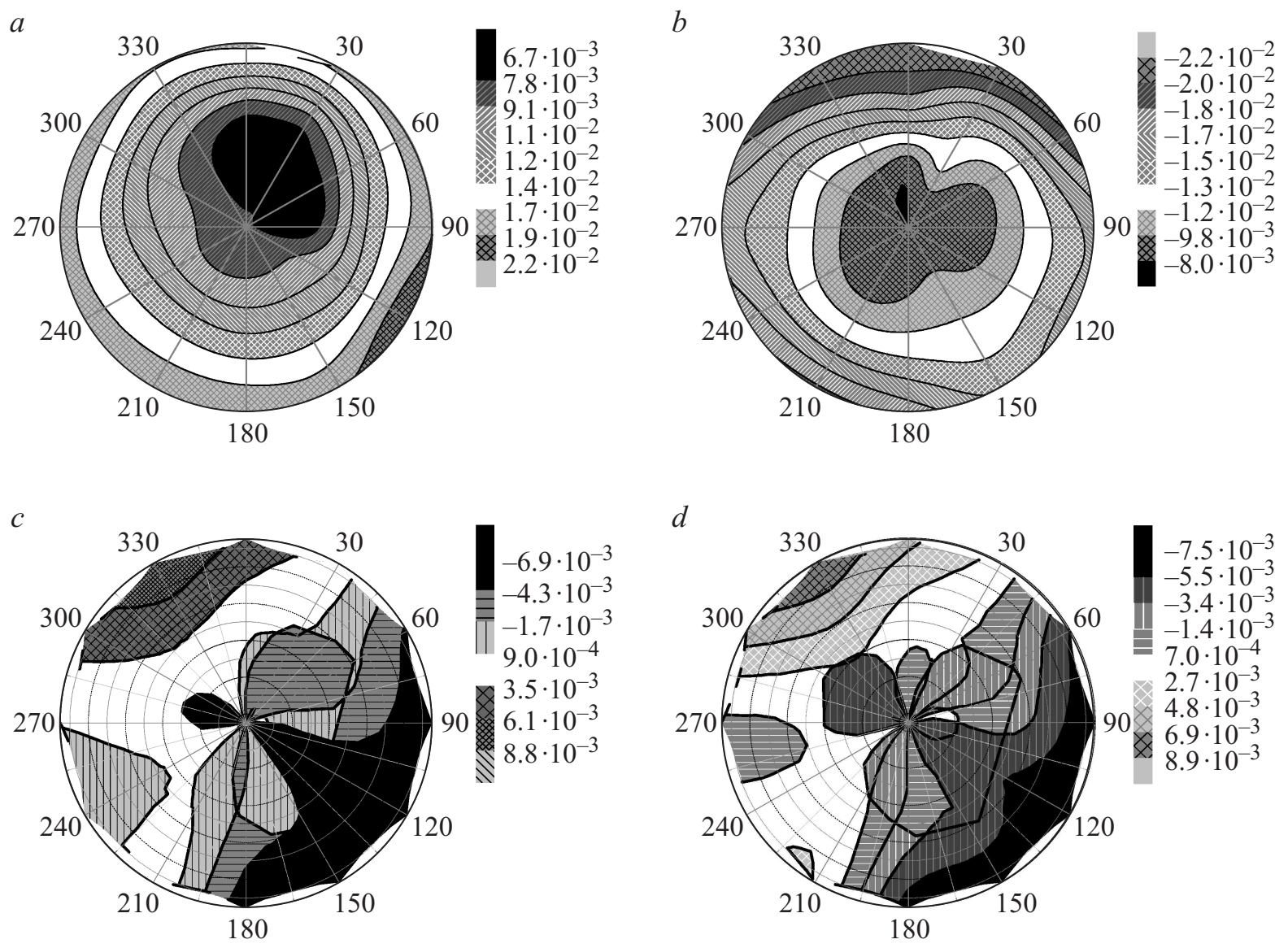

Рис. 2. Распределение остаточной намагниченности (в полярных координатах) в образцах с обработкой № 1 и № 2 . Цифры в верхнем правом углу соответствуют величине магнитной индукции.

Симметричность электрического взрыва тонких фольг дает возможность контроля как параметров импульса нагружения, так и параметров ударного импульса, прошедшего через образец. На рис. 1 представлена схема метода. Взрывающаяся фольга (1) зажимается между двумя одинаковыми волноводами (4), к одному из которых прижат исследуемый образец.

В качестве волноводов использовались цилиндры из высокопрочной стали $\varnothing 20 \times 18 \mathrm{~mm}$. Поверхности волноводов и образцов тщательно шлифовались и полировались. Качество граничных условий на контактных поверхностях волноводов и образцов и определяет в основном точность измерений.

Таблица 1. Параметры материала образцов. $\rho-$ плотность материала, $C$ - скорость звука, $E-$ модуль упругости, $\mathrm{HV}$ - микротвердость

\begin{tabular}{c|c|c|c|c}
\hline Fe-Cr-Co & $\begin{array}{c}\rho, \\
\mathrm{g} / \mathrm{cm}^{3}\end{array}$ & $\begin{array}{c}C, \\
\mathrm{~m} / \mathrm{s}\end{array}$ & $\begin{array}{c}E, \\
\mathrm{GPa}\end{array}$ & $\begin{array}{c}\mathrm{HV}, \\
\mathrm{MPa}\end{array}$ \\
\hline Обработка № 1 & $7.685 \pm 0.005$ & $6185 \pm 5$ & $294 \pm 2.5$ & $4225 \pm 5$ \\
Обработка № 2 & $7.695 \pm 0.005$ & $6055 \pm 5$ & $282 \pm 2.5$ & $2565 \pm 5$ \\
Обработка № 3 & $7.665 \pm 0.005$ & $6215 \pm 5$ & $296 \pm 2.5$ & $4255 \pm 5$
\end{tabular}

Измерения скоростей свободной поверхности образца и волновода осуществлялись лазерными дифференциальными интерферометрами либо непосредственно со свободных поверхностей, либо с применением „оконной“ методики $[8,9]$. Анализ профилей скорости свободной поверхности образцов дает возможность получить данные о динамическом пределе упругости, значениях откольной прочности и возможных фазовых переходах.

Перед проведением ударных испытаний проводилось измерение микротвердости, плотности материала и скорости упругих волн в образцах, после чего были рассчитаны упругие модули. Результаты измерений представлены в табл. 1.

\section{3. Результаты и обсуждение}

После проведения ударного нагружения образцов было обнаружено наличие остаточной намагниченности образцов № 1 и № 2, а также их фрагментов. Возникновение остаточной намагниченности указывает на реализацию магнитного фазового перехода, индуцированного в результате ударного нагружения.

Распределение остаточной намагниченности на поверхностях образцов измерялось датчиком Холла с 

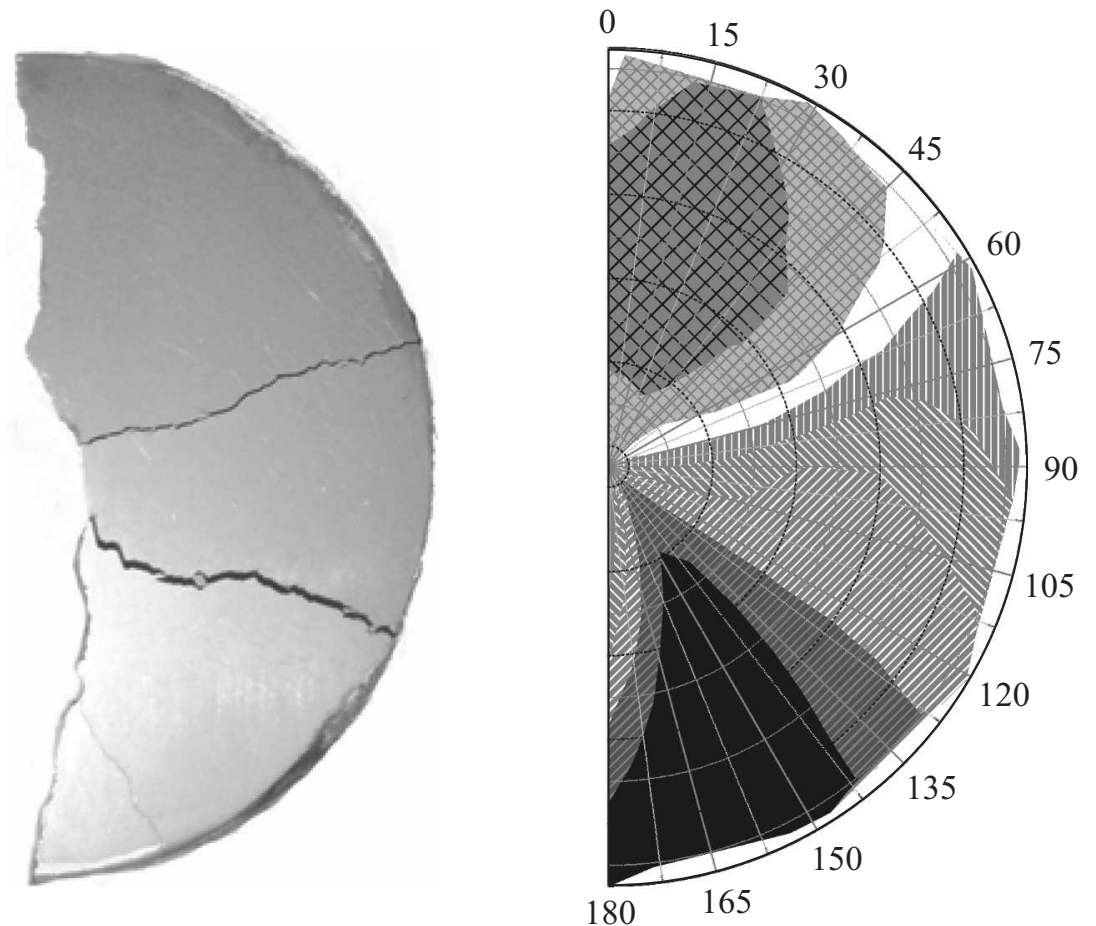

$-4.9 \cdot 10^{-3}$

$-3.8 \cdot 10^{-3}$

$-2.7 \cdot 10^{-3}$

$-1.7 \cdot 10^{-3}$

$-6.0 \cdot 10^{-4}$

$4.8 \cdot 10^{-4}$

$1.5 \cdot 10^{-3}$

$2.6 \cdot 10^{-3}$

$3.7 \cdot 10^{-3}$

180

Рис. 3. Сопоставление трещин и распределения намагниченности в образце после ударного воздействия.
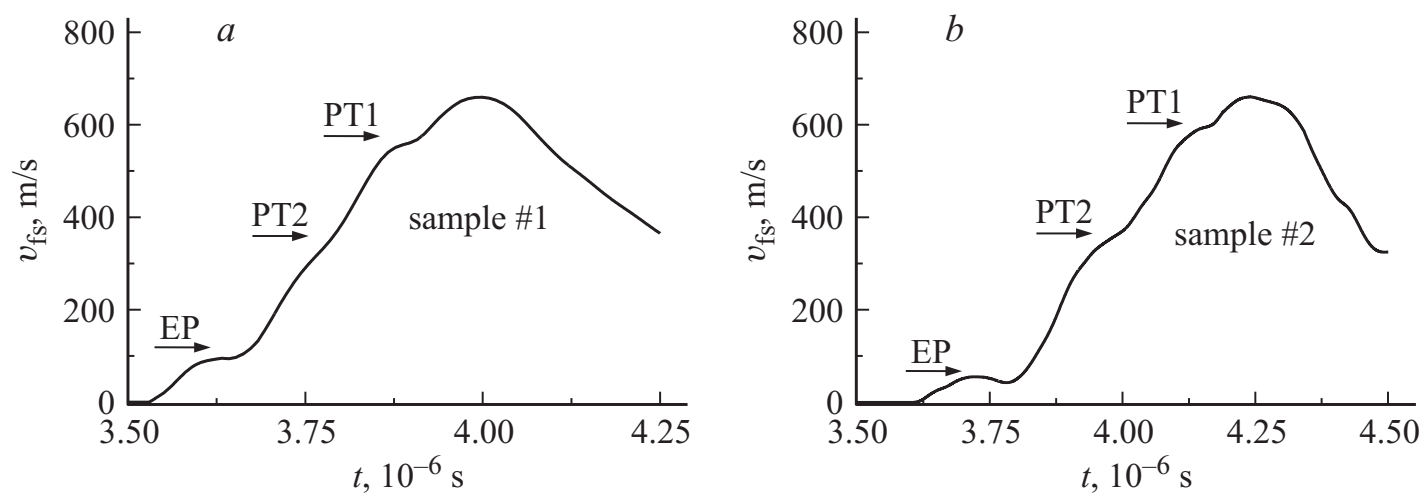

Рис. 4. Скорость свободной поверхности образца при выходе импульса напряжений.

диаметром рабочей поверхности $5 \mathrm{~mm}$. Поверхности образца были поделены на сектора с углом $30^{\circ}$ и окружностями с радиусами $5,10,15$ и $20 \mathrm{~mm}$.

На рис. 2 представлены примеры распределения остаточной намагниченности (в полярных координатах) в образцах с режимами обработки № 1 и № 2: на рис. $2, a, b$ для лицевой и обратной стороны образца с обработкой № 1, а на рис. 2,c,d для образца с обработкой № 2.

Результаты измерений демонстрируют существенную неоднородность распределения остаточной намагниченности по поверхности образцов. В некоторых образцах различалась только величина магнитной индукции (рис. 2, $a, b$ ), а в некоторых и ее знак (рис. 2,c,d).

Существенную роль в наличие такой неоднородности внес процесс и характер разрушения образцов в результате ударной нагрузки. Разрушение образцов протекало по нескольким механизмам: откольного механизма в центральной области образца, выбивания пробки (область ударного нагружения $\sim \varnothing 20 \mathrm{~mm})$, а также радиального разрушения в результате действия растягивающих напряжений. Отметим, что величина остаточной намагниченности в центральной области действия плоской волны напряжений во всех образцах была минимальна.

Корреляция распределения намагниченности с характером разрушения образца представлена на рис. 3 .

Наличие индуцированного магнитного фазового перехода подтверждается также характерным видом зависимости скорости свободной поверхности этих образцов. На рис. 4 приведены типичные временны́е профили скорости свободной поверхности образцов. 
Таблица 2. Результаты измерений. $\sigma_{e p}-$ напряжение упругого предвестника, $\sigma_{s p}-$ откольная прочность, $\sigma_{P T 1}-$ напряжение первого фазового перехода, $\sigma_{P T 2}$ - напряжение второго фазового перехода

\begin{tabular}{c|c|c|c|c}
\hline Обработка & $\sigma_{e p}, \mathrm{GPa}$ & $\sigma_{s p}, \mathrm{GPa}$ & $\sigma_{P T 1}, \mathrm{GPa}$ & $\sigma_{P T 2}, \mathrm{GPa}$ \\
\hline № 1 & 2.2 & 8.0 & 7.15 & 13.1 \\
№ 2 & 1.3 & 11.0 & 7.9 & 13.5 \\
№ 3 & 6.2 & 12.4 & нет & нет
\end{tabular}

Временны́е профили импульсов, прошедших через образцы, с одной стороны, имели вид, характерный для упругопластических материалов [10-12], а с другой, в образцах № 1 и № 2 наблюдались и существенные отличия (рис. $4, a, b)$. Помимо упругого предвестника (EP), на фронте видны два перегиба, отмеченные на рис. 4 как PT1 и РТ2. Такие характерные изменения фронта ударной нагрузки обычно наблюдается при полиморфных фазовых переходах в материалах, например при фазовом переходе $\alpha-\varepsilon$ в железе и его сплавах [10-12]. В области фазового перехода ударная адиабата претерпевает изломы, что и проявляется на фронте импульса скорости свободной поверхности.

Значения скорости свободной поверхности $V_{s f}$ связаны с напряжениями в образце простым соотношением $[10,11]$

$$
\sigma=0.5 \rho c_{L} V_{s f},
$$

где $\rho-$ плотность материала; $c_{L}-$ продольная скорость звука.

Наблюдаемый в образцах с обработкой № 1 и № 2 фазовой переход РТ1 с величинами напряжений $\sigma_{P T 1}^{\text {№ } 1} \cong 1.31 \mathrm{GPa}$ и $\sigma_{P T 2}^{\text {№ } 2} \cong 1.35 \mathrm{GPa}$ как раз и соответствует этому хорошо известному для железа и его сплавов фазовому переходу $\alpha-\varepsilon[10,12]$, с пороговым значением которого согласуются результаты измерений.

Помимо этого фазового перехода наблюдается еще один фазовый переход (РТ2) при напряжениях $\sigma_{P T 2}^{№ 1} \cong 7.12 \mathrm{GPa}, \sigma_{P T 2}^{\text {№ } 2} \cong 7.92 \mathrm{GPa}$.

В закаленном сплаве (образец № 3) отмеченных фазовых переходов и остаточной намагниченности не наблюдалось.

Эффект возникновения остаточной намагниченности в ферромагнитных сплавах наблюдался при различных механических нагрузках [13-16]. Например, в $[13,14]$ обнаружены фазовые переходы в никелевых суперсплавах после ударного нагружения с давлениями $20 \mathrm{GPa}$ и $100 \mathrm{GPa}$. В работе [15] отмечалось возникновение намагниченности в стали 110Г13Л в результате воздействия динамических нагрузок, а в [16] изучался эффект техногенной намагниченности горных пород. Результаты этих исследований показали, что пластическая деформация и обусловленные ею эволюции структуры материалов определяют возможность фазовых переходов. Однако данных о пороговых значениях давлений магнитных фазовых переходов при ударных нагрузках в литературе практически не удается обнаружить.
Обнаруженный фазовый переход также может быть обусловлен структурными перестройками в сплаве, например, изменением соотношения $\alpha 1$ и $\alpha 2$ фаз, и сопровождающим их ориентационным магнитным переходом за счет возрастания энергии магнитного взаимодействия в локализованных полосах пластического сдвига. Детализация причин такого структурного магнитного перехода требует дополнительных достаточно обширных исследований.

Таким образом, влияние термообработки сказывается не только на количественных характеристиках прочности и пластичности (табл. 2), но и на возможности фазовых переходов при динамических нагрузках и их пороговых значениях.

Значительный интерес представляет вопрос о возможности ориентационного магнитного фазового перехода в сплавах системы $\mathrm{Fe}-\mathrm{Cr}-\mathrm{Co}$ в условиях статического нагружения.

К настоящему времени существует общепризнанное понимание того, что ориентационный магнитный фазовый переход неотделим от перестройки структуры материала, обусловленной, в частности, пластической деформацией, а также вкладом эффектов связанности магнитных полей и полей механических напряжений. В работах [17-19] показано, что практически всегда структурные фазовые переходы сопровождаются спинпереориентационными фазовыми переходами, а изменения в магнитной подсистеме, в свою очередь, могут приводить к изоструктурным фазовым переходам.

Однако при изучении механических свойств сплавов системы $\mathrm{Fe}-\mathrm{Cr}-\mathrm{Co}$ традиционными методами (прокатка, одноосное растяжение и т.д.), напряжения в которых не превышали $\sim 2-3 \mathrm{GPa}[3,4,20]$, не было обнаружено фазовых переходов. При этом отмечалось существенное увеличение доли ферромагнитной фазы с увеличением степени пластической деформации, что позволяет предполагать возможность ориентационного фазового перехода и при статических нагрузках.

Однозначный ответ на это вопрос требует проведения достаточно трудоемких исследований. Прочность таких материалов при статических нагружениях достаточно мала - предел прочности сплавов системы $\mathrm{Fe}-\mathrm{Cr}-\mathrm{Co}$ не превышает $\sim 2-3 \mathrm{GPa}$, что в несколько раз ниже измеренных в нашей работе значений фазового перехода ( 7-8 GPa). При этом следует иметь в виду существенное отличие термодинамики статических и динамических испытаний - обычно изотермический процесс в первом случае и адиабатический во втором, что существенным образом может сказываться на вероятности и критических параметрах фазовых переходов.

\section{4. Заключение}

Исследования высокоскоростного деформирования магнито-твердого сплава $\mathrm{Fe}-\mathrm{Cr}-\mathrm{Co}$ позволили обнаружить структурный магнитный фазовый переход, индуцированный ударным импульсом, и определить пороговые 
значения давлений (7-8 GPa) этого перехода. Измерения показали существенную неоднородность распределения остаточной намагниченности по поверхности образцов. При этом распределение намагниченности хорошо коррелирует с траекторией трещин в образце, что может говорить о связи процессов разрушения с процессами образования магнитных полей в образце.

\section{Список литературы}

[1] M. Kaneko, M. Homma, T. Minowa. IEEE Trans. Magn. 12, 6, 977 (1976).

[2] T. Minowa, M. Okada, M. Homma. IEEE Trans. Magn. 16, 3, $529(1980)$

[3] И.М. Павлов, Г.Н. Мехед, Л.А. Кавалерова, И.М. Миляев, Ж.А. Васильева. В сб.: Пластическая обработка металлов и сплавов / Под ред. Н.В. Агеева. Наука, М. (1979). С. 213.

[4] А.И. Миляев, Ю.К. Ковнеристый, С.П. Ефименко, Г.Ф. Корзникова. Физика и химия обработки материалов 3, 86. (2003).

[5] Y. Sudenkov, S. Atroshenko, I. Smirnov, N. Naumova, X. Sun. Appl. Mechan. Mater. 566, 542 (2014).

[6] С.А. Атрошенко, Ю.В. Судьенков, Х.Y. Sun, Н.Ф. Морозов, И.В. Смирнов, Н.С. Наумова. Деформация и разрушение материалов 8, 2 (2014).

[7] Ю.В. Судьенков, И.В. Смирнов. Патент РФ, № 2507498, 20.02.2014.

[8] L.M. Barker, R.E. Hollenbach. Rev. Sci. Instr. 36, 11, 1617 (1965).

[9] J.R. Assay, L.M. Barker. J. Appl. Phys. 75, 6, 2540 (1974).

[10] Ударные волны и экстремальные состояния вещества / Под ред. Л.В. Альтшулера и др. Наука, М. (2000). 425 с.

[11] Б.Л. Глушак, В.Ф. Куропатенко, С.А. Новиков. Исследование прочности материалов при динамических нагрузках. Наука, Новосибирск (1992). 292 с.

[12] Г.И. Канель, С.В. Разоренов, А.В. Уткин, В.Е. Фортов. Ударно-волновые явления в конденсированных средах. Изд-во. Янус-К, М. (1996). 407 с.

[13] Н.В. Казанцева, Н.И. Виноградова, М.Б. Ригмант, А.Н. Пирогов. Деформация и разрушение металлов 9, 33 (2009).

[14] Н.В. Казанцева, Б.А. Гринберг, Е.В. Шорохов, А.Н. Пирогов, Ю.А. Дорофеев. ФММ 99, 5, 1 (2005).

[15] В.В. Казанцева, Л.И. Квеглис. Журнал Сибирского федерального университета. Техника и технологии 2, 4, 376 (2009).

[16] В.А. Тюремнов. Вестник МГТУ 10, 2, 304 (2007). 